\title{
Japanese poised to dominate in superconductors as well?
}

Tokyo

WHAT is happening in high-temperature superconductor research in Japan? Is Japan Incorporated ready to conquer the world? Not yet. Research is under way on a broad front but is largely uncoordinated, as government agencies and ministries manoeuvre to stake out territory and preserve their interests.

Since a group of researchers at Tokyo University confirmed superconductivity at about $30 \mathrm{~K}$ in a copper-oxide ceramic at the end of last year, research on the new materials in Japan has exploded. The April and May special issues of the Japanese Journal of Applied Physics contain nearly 200 papers on the new superconductors by several hundred scientists in about 80 laboratories throughout Japan. And barely a day goes by without the announcement of another 'breakthrough'.

Much of the effort, however, involves unnecessary duplication. On 4 March, the Science and Technology Agency's National Research Institute for Metals in Tsukuba announced that it had succeeded in making a high $T$ ceramic, only to find that the same announcement had been made the day before by its Tokyo research institute. Researchers at the two laboratories were apparently unaware that they were making the same ceramics even though both had representatives on the agency's research committee on hightemperature superconductors. The committee, with representatives drawn from the universities, industry and the agency's laboratories, was formally set up in February but began informal meetings at the end of last year. The committee's principal job is to organize workshops and symposia; the first symposium was held on 1 May with I. Bednorz of IBM Zurich as guest speaker.

According to Koichi Kitazawa of Tokyo University, one of the committee members, the Science and Technology Agency has been very quick off the mark and has played an important role in disseminating news. The right 'atmosphere' to win financial support from the Ministry of Finance is being created. The new superconductors also provide a golden opportunity to boost the agency's National Research Institute for Metals whose fortunes have been declining along with those of the iron, steel and aluminium industries. On 28 May, the agency announced the establishment of a 50-man research centre at the Tsukuba site next spring to carry out basic and applied research on the new ceramics.

When it comes to funding research, though, the agency has been beaten off the mark by, surprisingly, the Ministry of
Education. Casting aside its conservative image, the ministry has taken the extraordinary step of extending a major fixedterm grant, something that has only previously been done in the case of a natural disaster. A special research project to investigate new superconducting materials headed by Professor Nakajima of Tokai University (formerly of Tokyo University) is to be extended at a cost of Y180 million (\$1.3 million). In addition, Professor Kazuo Fueki of the Tokyo University group has been awarded Y36 million by the ministry for this fiscal year (April 1987-March 1988). And Professor Shoji Tanaka, leader of the Tokyo University group, is a strong candidate for one of the ministry's special distinguished grants which are announced at the end of this month. Running from three to five years, the grants are usually worth Y100200 million (about $\$ 1$ million).

But the biggest government backer of technology development, the Ministry of International Trade and Industry (MITI), has yet to show its cards. MITI has long been a strong supporter of superconductor research. Companies such as Toshiba and Hitachi, nurtured in MITI's magnetohydrodynamic project, and aided by Japan National Railway's bid to build a high-speed train levitated on superconducting magnets, have gone on to supply many of the magnets for US particle accelerators. Josephson junction research has also been supported within the national supercomputer project. $\mathrm{Al}$ though US companies, including IBM, abandoned similar work, researchers at NEC, Hitachi and Fujitsu remain confident that a Josephson junction computer can be built by the twenty-first century.

MITI money is also being funnelled to private companies through the Electric Power Central Laboratory in Tokyo, thereby allowing eight companies all to continue production of conventional superconducting wire, despite the comparatively small size of the Japanese market. It was from them that the first reports of the manufacture of high-temperature superconducting wires emanated. First off the mark was Fujikura Densen with $\mathrm{La}-\mathrm{Sr}-\mathrm{Cu}$ oxide encasedin drawn-out tubes of copper and steel. Then on 2 April, Toshiba released pictures of wire fashioned from $\mathrm{Y}-\mathrm{Ba}-\mathrm{Cu}$ oxide. Although the current-carrying capacity of the wire was initially very low (a few amps per square centimetre), within a month Toshiba had reached $520 \mathrm{~A} \mathrm{~cm}^{-2}$ and now Hitachi claims the record at $4,000 \mathrm{~A} \mathrm{~cm}^{-2}$ for ceramic wire $(0.8 \mathrm{~mm}$ diameter $)$ encased in silver.

Despite these projects, however, MITI

\section{Just five years from superconductor cable Washington}

THE US Department of Energy (DoE) is showing unusual alacrity in pushing for research on the new superconductors. Motivated by constant but uncertain rumours of furious Japanese activity, DoE officials have taken some considerable steps towards an organized national effort in this new technology.

A series of conferences to promote collaboration between the national laboratories, universities and industry is already under way, but DoE has now gone beyond this cheerleading role and has given Argonne National Laboratory a specific brief to produce a practical superconducting wire, operating in liquid nitrogen, in five years. (Argonne researchers have already made 'wires' by embedding superconducting grains in a plastic base.) The aim of the programme, in which Brookhaven and Ames (Iowa) Laboratories will also participate, is to make a cable suitable for electric transmission lines.

DoE also announced last week that it is setting up a computerized database to help US scientists to cope with the huge flow of results. Secretary of Energy John S. Herrington said that the normal channels of scientific communication are being overwhelmed, and that the DoE, by expanding its existing systems, could expedite the flow of information. The database will be accessible through electronic mail, and will be open to anyone who pays an entry fee.

The impetus for these initiatives is apparently coming from the top. At DoE headquarters, 'research applications' and 'Japan' are whispered in the same breath, and the current political climate is ideal for any venture which seeks to encourage US industry.

David Lindley

has yet to formulate a policy on the new superconductors. Some of the problems are internal. There are fears that a new project may siphon off funds from projects already established - to the Ministry of Finance, superconductors are all the same be they ceramic or otherwise.

After a hearing of the science and technology committee in the lower house of the Diet on 28 May, Professor Shoji Tanaka called for a national project to develop applications, such as a magnetically levitated train. Also present at the hearing was Yoshihiro Kyotani, head of Japan's linear motor car (MAGLEV) project. But ruling party politicians suggested that the project should be international and might even be proposed at the Venice summit next week.

Tanaka denies that he is suggesting that Japan set up a research association similar to the well-known VLSI (very large-scale integrated circuit) project of the late 1970s 


\section{Superconductivity at room temperature}

New Delhi

Scientists at the National Physical Laboratory (NPL) in New Delhi are proudly claiming to have found the hottest ever superconducting oxide phase. It shows superconductivity all the way up to $+26^{\circ} \mathrm{C}$ (299 K), or room temperature.

The development was officially made public before publication in a scientific journal in an attempt to ensure its legitimate place in the race in superconductivity both in India and elsewhere. Indian scientists frequently complain that although they are keeping pace with the latest developments in Japan and the United States, their work is often dated by the time it is printed in international scientific journals.

The NPL discovery was made in multiphase samples of $\mathrm{Y}(\mathrm{Ba}, \mathrm{Sr})_{2} \mathrm{Cu}_{3} \mathrm{O}_{8}$ prepared by the direct oxide-mixing technique. The typical resistance-versus-termperature curves show a sharp drop in resistance above $230 \mathrm{~K}$ followed by a gradual metallike decrease of resistance with temperature. A study of the inverse a.c. Josephson effect revealed the presence of a phase superconducting up to $+26^{\circ} \mathrm{C}$. "It is the hottest superconducting phase observed so far", said Dr A.V. Narlikar, the leader of the NPL team.

Because the sample had many phases, the studies were repeated in several different samples. In each of them, superconductivity was found to persist up to temperatures of 15 to $26{ }^{\circ} \mathrm{C}$, said Narlikar. Studies also showed that the $26^{\circ} \mathrm{C}$ phase constituted the bulk of the sample. Narlikar said his team is now working on isolating this phase. "When we do that, we will really have a room-temperature superconductor", he said. K.S.Jayaraman

which drew together Japan's electronics giants with MITI support and helped power the conquest of world semiconductor memory markets. But it is no secret that Tanaka has close connections with Japanese industry, in particular Toshiba and Hitachi where several of his present and former students carry out research.

Other scientists who are on the government/industry university committee established by MITI to study the new superconductors doubt that the ministry will form a research association. Rather, they think that a medium-scale project under the category "basic research for future industries" may be possible. These projects which cover new materials, biotechnology and new molecular devices (including biochips) typically receive funding of a few thousand million yen (around $\$ 10$ million) per year. But the earliest such a project could be set up would be 1988 , and consensus would have to be reached in MITI within the next few months.

Meanwhile, research in industry is largely "free-style" with no particular coordination, government or otherwise, according to Dr Janshen Tsai, supervisor of the advanced device research laboratory at NEC. NEC has fewer than 10 researchers working full-time on the new superconductors but there are about 30 or 40 part-timers and many more are interested in joining the research, which covers primitive Josephson junction devices and thin films.

Researchers at Toshiba's Research and Development Centre in Kawasaki, on the other hand, seem to be interested primarily in wires and thin films, and they have no intention of pursuing Josephson junction research. Osamu Horigami, Toshiba's chief research scientist at the centre's energy science and technology laboratory, has 28 researchers working on superconductors and cryogenics and they are collaborating with scientists in the metals and ceramics laboratory of the same centre. Horigami says his laboratory began investigating superconducting ceramics about six years ago in collaboration with Professor Tanaka of Tokyo University — but they gave up when they reached a critical temperature of only $18 \mathrm{~K}$.

How much money are these companies putting into the research effort? Company officials will quote only the percentage of total sales devoted to all research and development (8-7 per cent for Toshiba and 10 per cent for NEC). But Dr Ushio Kawabe of Hitachi says that in general they budget about $\mathrm{Y} 10$ million $(\$ 70,000)$ per researcher per year.

Patents are being sought apace. Sumitomo Electric Industries, a large wire and cable manufacturer, is reported to have applied for 800 patents on superconducting technology covering materials, processing and application. Many of the leading researchers in Japan have also taken out patents, although nobody knows who was first.

Tanaka fears that Japan may once again be criticized for failing to contribute to basic research. He and his colleagues have been publishing heavily to make the world aware of their efforts as students grind out ceramics in the laboratory (now up to processing 48 samples a day). And to drive home the point, 1,000 copies of the April special issue of the Japanese Journal of Applied Physics, weighing 0.7 tonnes, were airfreighted to the United States and distributed free of charge at the Material Research Society meeting in San Francisco. Mitsui Co Ltd agreed to cover the Y3 million $(\$ 20,000)$ air freight costs as a "contribution to basic science".

Other Japanese researchers are less concerned about such matters. "Our interest is how to get wire and devices using this material", says Horigami of Toshiba.

\section{Supercomputer stand}

\section{Bangalore}

US efforts to limit high technology exports on the grounds of national security may jeopardize the prospects for an Indo-US supercomputer deal. India wants the United States to supply a Cray-XMP-24 model, but the Reagan administration's security adviser, Frank C. Carlucci, is urging it to accept the Cray-XMP-14. In explanation, Robert Dean, the National Security Council's staff specialist on advanced technology transfer, says "We know this supercomputer [Cray-XMP-24] is something that the Soviets would very much like to get".

Carlucci says India and the United States have agreed on safeguards for the supercomputer as well as increasing levels of US cooperation in economic and technological fields. In New Delhi, Rajiv Gandhi's government, rocked as it is by political controversies, has yet to find time to assess the US offer.

R.R.

FBA labs are reprieved London

STAFF at the Freshwater Biological Association (FBA), threatened earlier this year with up to 30 redundancies because of a

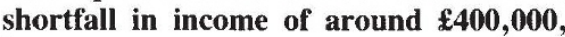
have won a temporary reprieve. Following discussions between FBA senior management and the Natural Environment Research Council, which provides the bulk of FBA's funds through an annual grantin-aid, 12 staff will now lose their jobs. The situation will be reviewed at the end of August. FBA's future now depends on its ability to increase its income from private contracts. The association, whose 103 staff study the ecology of rivers and lakes at laboratories in Dorset and Cumbria, fears that too much short-term commissioned work will result in a gradual abandonment of longer-term, less immediately lucrative studies. S.L.H.

\section{Erasmus is adopted}

London

Twenty-FIVE thousand students could benefit from a new European Community Action Scheme for the Mobility of University Students (ERASMUS) over the next three years. The scheme has a budget of $£ 59$ million. The new grants will be available to European Community students wishing to study in other member states. Despite its name, the scheme will be open to students in all forms of higher education and there are to be no subject restrictions.

A European University Network will be set up to promote inter-university student exchange programmes and an improved system of academic comparison will assist in the placement of foreign students. A pilot scheme to be run in twenty universities will try out a 'credit transfer' scheme like that used in the United States. S.J.H. 